\title{
Frequency analysis of river water quality using integrated urban wastewater models
}

\author{
Guangtao Fu and David Butler \\ Centre for Water Systems, College of Engineering, Mathematics and Physical Sciences, \\ University of Exeter, North Park Road, Harrison Building, Exeter EX4 4QF, UK \\ Email: g.fu@exeter.ac.uk, d.butler@exeter.ac.uk
}

\begin{abstract}
In recent years integrated models have been developed to simulate the entire urban wastewater system, including urban drainage systems, wastewater treatment plants, and receiving waterbodies. This paper uses such an integrated urban wastewater model to analyze the frequency of receiving water quality in an urban wastewater system with the aim of assessing the overall system performance during rainfall events. The receiving water quality is represented by two indicators: event mean dissolved oxygen concentration and event mean ammonium concentration. The compliance probability of the water quality indicators satisfying a specific threshold is used to represent the system performance, and is derived using the rainfall events from a series of 10 years' rainfall data. A strong correlation between the depth of each rainfall event and the associated volume of combined sewer overflow (CSO) discharges is revealed for the case study catchment, while there is a low correlation between the intensity/duration of the rainfall event and the volume of the CSO discharges. The frequency analysis results obtained suggest the event mean dissolved oxygen and ammonium concentrations have very different characteristics in terms of compliance probabilities at two discharging points for combined sewer overflow and wastewater treatment plant effluent, respectively. In general, the simulation results provide an understanding of the performance of the integrated urban wastewater system and can provide useful information to support water quality management.
\end{abstract}

\section{Keywords}

Combined sewer overflow, frequency analysis, integrated modelling, urban drainage system, water quality

\section{INTRODUCTION}

There is increasing concern about river water quality in the recent years in relation to the adverse impacts from population growth, land use change, and climate change (He et al. 2008; Semadeni-Davies et al. 2008a,b; Fu et al. 2009). New legislation has been introduced worldwide to protect surface water quality, human health and aquatic environment. For example, the EU Water Framework Directive (WFD) was adopted in 2000 and requires member states to achieve 'good' ecological and chemical status in all waterbodies by 2015 (Council of the European Communities, 2000). Similarly in China, the Environmental Quality Standard for Surface Water came into effect in 2002, with stricter standards in comparison to the preceding legislation (Ministry of Environmental Protection, 2002). These new regulations pose a new challenge for water systems modeling and water quality 
management.

Understanding the effects of storm events on receiving water quality is very important for water quality management, particularly in urban areas. Combined sewer overflow (CSO) discharges, directly related to storm events, are regarded as one of the main sources for receiving water pollution. Rauch and Harremoës investigated the relationship between CSO discharges and Dissolved Oxygen (DO) concentration in the receiving water through different control strategies (Rauch and Harremoës 1998). Even et al. (2007) simulated the contribution of CSO discharges to the oxygen consumption in the river Seine, France. However, Lau et al. (2002) were first to demonstrate that CSO discharges are not necessarily closely related to the receiving water quality (in terms of DO and ammonium concentrations) in an integrated urban catchment. Schindler et al. (2008) used an integrated urban wastewater model to investigate the statistical characteristics of receiving water quality. Recently, Alp and Melching (2009) moved a step further to look at the relationship between receiving water quality and rainfall characteristics, and found that there is a strong relation between rainfall depth and the duration of the storm effects on the water quality of the Chicago Waterway System, and suggested that this relation can be used to predict the duration of the storm effect on water quality.

The aim of this paper is to analyse the compliance frequency of receiving water quality in an integrated urban wastewater system and thus provide an estimation of overall system performance. Receiving water quality is represented by two indicators: DO Event Mean Concentration (EMC) and ammonium EMC. Compliance frequency is defined as the probability of a water quality indicator satisfying a specific threshold. A series of 10 years' rainfall data is used for analysis and a previously developed integrated urban wastewater system model is used for evaluation. The compliance probabilities of DO and ammonium EMCs obtained from simulation are discussed and finally conclusions are presented at the end of the paper.

\section{MATERIALS AND METHOD}

\section{The case study catchment}

The catchment consists of a combined sewer system, a treatment plant and a river system (Fig. 1), and it was defined by Schütze (1998) and previously studied in detail for real time control problems (Zacharof et al. 2004; Fu et al. 2008).

The sewer system is divided into seven sub-catchments, which have in total an area of 725.8 ha and a population of 152,000. There are four on-line pass through storage tanks at the downstream of sub-catchments SC2, SC4, SC6 and SC7, respectively. The storage is roughly uniformly distributed across the sub-catchments, with an average volume of $18 \mathrm{~m}^{3} / \mathrm{ha}$.

The wastewater treatment plant has the capacity to treat an average dry weather flow of $27,500 \mathrm{~m}^{3} / \mathrm{d}$. It consists of a storm tank, primary clarifier, and activated sludge reactor and secondary clarifier. The storm tank has a volume of $6750 \mathrm{~m}^{3}$, and it provides additional storage to the sewer system. As a result, the average storage of the urban catchment is increased to $27 \mathrm{~m}^{3} / \mathrm{ha}$.

The river system is $45 \mathrm{~km}$ in length and is equally divided into 45 reaches for simulation. The 
CSO discharges are assumed to be at reach 7, and storm tank overflows and treatment plant effluent at reach 10 . The river base flow is $129,600 \mathrm{~m}^{3} / \mathrm{d}$, resulting in a $1: 5$ dilution ratio of dry weather treatment plant discharges to the river base flow. The data, such as the boundary conditions for concentrations, were defined by Schütze (1998) and are used in this study.

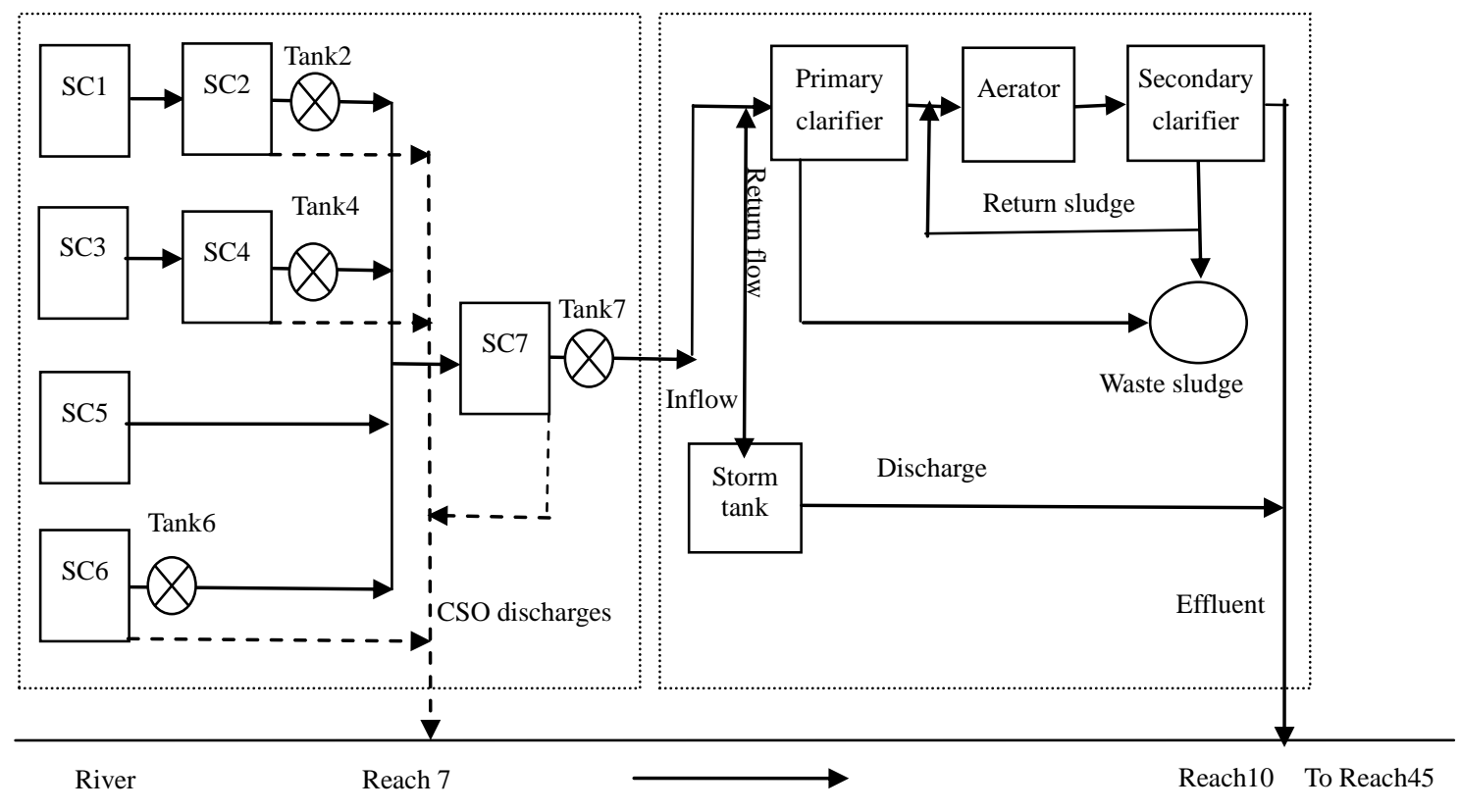

Fig. 1 Schematic representation of the integrated urban wastewater system. SCx represents the xth sub-catchment, and the dash lines show CSO discharge from the storage tanks, located at the downstream of SC2, 4, 6 and 7.

A series of 10 years' rainfall data were used to represent the rainfall characteristics in the urban catchment. In order to assess the system performance relevant to rainfall events, the rainfall series was separated into rainfall events using a 20-minute time interval between two consecutive events. A total of 3400 events were derived and used for simulation, and the histograms for rainfall depth and duration are shown in Fig. 2. The $y$-axis of Fig. 2 shows the relative frequency, i.e., the number of events in a bin normalized by the total number of rainfall events. It can be seen that rainfall depth and duration have different shapes but both have a long upper tail, indicating extreme events have a very low frequency. 

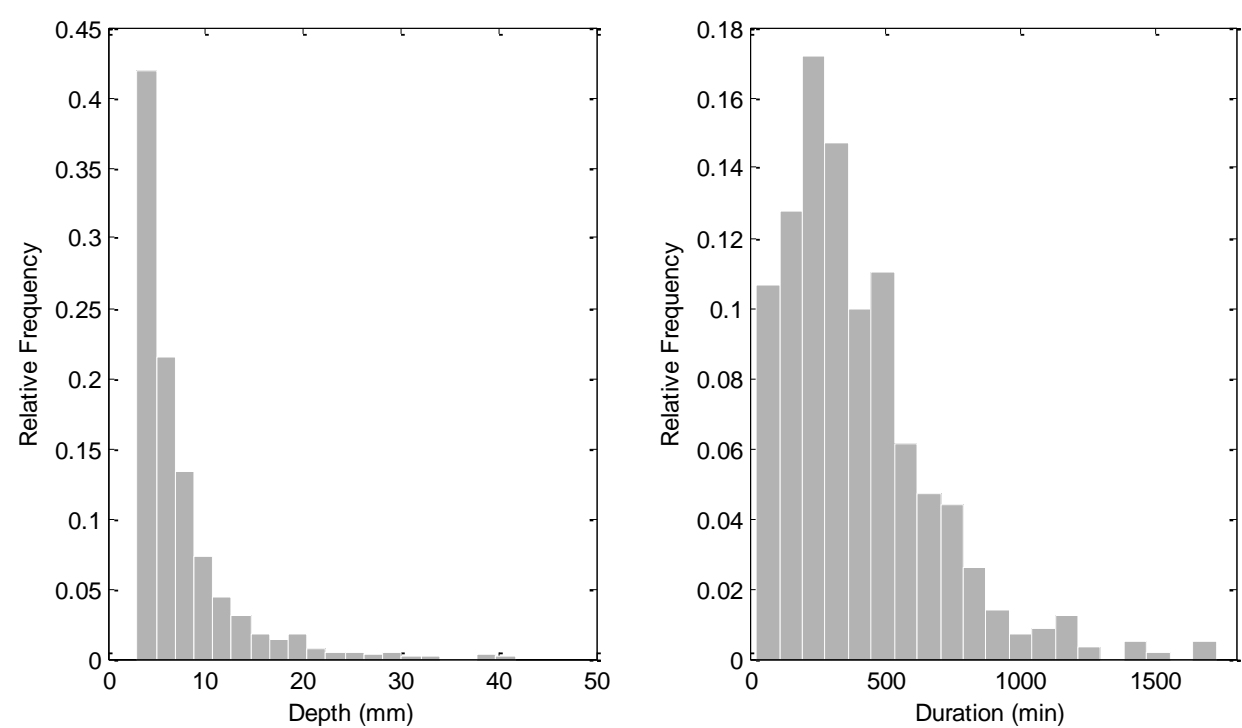

Fig. 2 Histograms of rainfall depth and duration.

A 100-day period with the dry weather conditions was simulated for the integrated system and the resulting system states were used as the starting states for the simulation of rainfall events. This ensures that the boundary conditions, effluents from the wastewater treatment plant etc. are exactly the same for each individual rainfall event, and that the impacts of rainfall on receiving water quality can be assessed without the influence of system control.

\section{Integrated model}

Since the 1990s, integrated models have been developed for urban wastewater systems including urban drainage systems, wastewater treatment plants, and receiving water bodies, with the view to improving system performance and receiving water quality (Rauch et al. 2002; Achleitner et al. 2007; Candela et al. 2012). Use of the integrated models have been focused on development of integrated control strategies (Schütze 1998; Vanrolleghem et al. 2005).

The integrated model used in this paper was developed in the MATLAB/SIMULINK environment using SIMBA 5.0 from IFAK system $\mathrm{GmbH}$, Germany. This tool provides a library of blocks for the sewer system, treatment plant and river systems, which allows users to build models graphically by dragging, dropping and linking selected blocks. The integrated model is able to simulate various hydraulic and biochemical processes of the three sub-systems in a single simulation environment. It has been used for development of multi-objective control strategies (Fu et al. 2008), impact analysis of urbanization (Fu et al. 2009), and development of mitigation measures for urbanization (Fu et al. 2010). This paper will use the integrated model to investigate the impacts of rainfall events on receiving water quality and assess the system performance in terms of compliance probabilities of chosen water quality indicators. This analysis can be achieved only by integrated modeling of urban wastewater systems (See, e.g., Candela et al. 2012).

In the integrated model used in this paper, the sewer system considers surface runoff and pollutant wash-off in impervious and pervious catchment areas, flow and pollutant transport in sewers and storage tanks. The Horton approach is used for long-term simulation of 
infiltration. Flow transport within a sub-catchment is simulated by using the cascaded linear reservoir method. The Activated Sludge Model No.1 is used to simulate wastewater treatment plants. The EPA storm water management model (SWMM 5.0) is used for hydrodynamic simulation of water and pollutant transport in the receiving river, considering discharges from the sewer system and wastewater treatment plant. Pollutants simulated in the river include biochemical oxygen demand, ammonium and DO. The concentration of suspended solids is not considered as it is not a concern in the river studied. The model was initially constructed and validated against industrial data by Schütze (1998), and is suitable for the purpose of this study.

\section{RESULTS AND DISCUSSION}

The receiving water quality is represented by two indicators: DO and ammonium concentrations. The EMC is normally used to estimate the loadings to receiving water bodies during a rainfall event, and is used here for both DO and ammonium concentrations as a good measure to assess the impact of rainfall events. To evaluate the system performance during rainfall events, the compliance frequency is thus defined as the probability of a water quality indicator (DO or ammonium) satisfying a specific threshold.

Fig. 3 shows the compliance probabilities for DO and ammonium EMCs at three different reaches of the receiving river, i.e., Reaches 7, 10 and 40. Reaches 7 and 10 are discharging points for CSOs and wastewater treatment plant effluent, respectively, and Reach 40 is the last reach of the river simulated and is a critical reach in terms of DO concentration. The results show a significant difference in the cumulative probabilities between Reach 7 and the other two reaches. That is, Reach 7 has the highest (the best) DO EMCs and the highest (the worst) ammonium EMCs. This implies the CSO discharges have a different impact on DO and ammonium. Both DO and ammonium EMCs are very stable around $8.50 \mathrm{mg} / \mathrm{l}$ and 3.80 $\mathrm{mg} / \mathrm{l}$, respectively, for a significant amount of rainfall events. Similarly, at Reach 10, the wastewater treatment effluent also has a different impact on the two water quality indicators. As revealed by Fig. 3, there is a significant variation in DO EMCs arranging from 8 to $1 \mathrm{mg} / \mathrm{l}$. On the contrary, the ammonium EMCs are very stable around $1.50 \mathrm{mg} / \mathrm{l}$ for a significant amount of rainfall events. This is mainly because DO concentration is much more complex and is influenced by many pollutants and processes such as carbonaceous biochemical oxygen demand, sediment oxygen demand, algal growth and death etc. The EMC can be compared with some standards to assess the compliance during rainfall events. The threshold of $4 \mathrm{mg} / \mathrm{l}$ is assumed here for the two indicators according to the Urban Pollution Management Manual (Foundation for Water Research 1998). As shown in Fig.3, the compliance probability of DO for this threshold is $92.5 \%$, and the compliance probability of ammonium is $98.4 \%$ at Reach 40 . The compliance probabilities at Reach 7 are very high although this reach has a CSO discharge point. This is because the frequency of extreme events is very low as shown in Fig. 2 and most events do not trigger CSO discharges. 

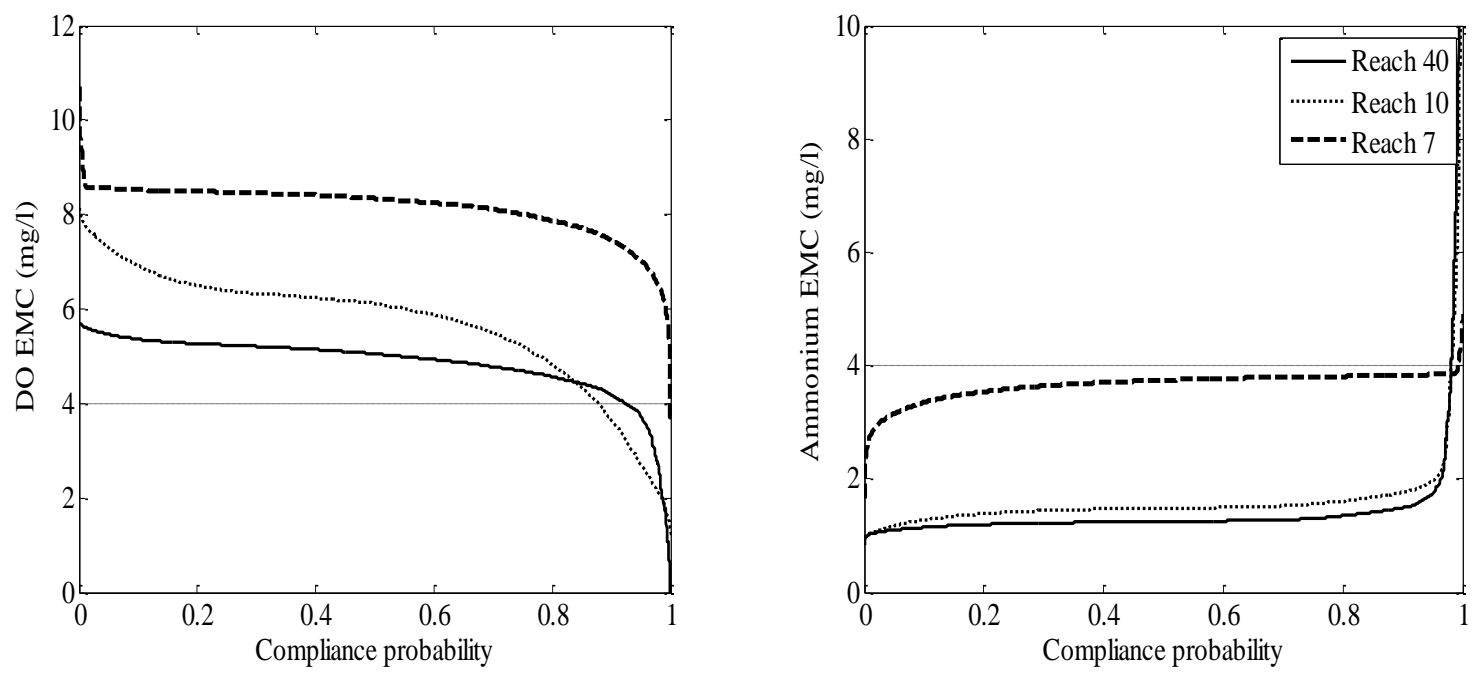

Fig. 3 Compliance probabilities of ammonium and DO event mean concentrations.

To investigate the impacts of rainfall events on CSO discharges, the scatter plots between rainfall variables (depth, duration and intensity) and CSO volume are shown in Fig. 4. There are no CSO discharges for rainfall events with a depth of less than $5 \mathrm{~mm}$. For bigger events, there is a close relationship between rainfall depth and CSO volume, and the Pearson correlation coefficient for all the events is 0.8. It can be seen from Fig. 4 that there is no close relationship between rainfall duration and CSO volume, with a correlation coefficient of 0.31 . Similarly, the correlation between rainfall intensity and CSO volume is low, which implies that rainfall intensity cannot be used to predict CSO volume.
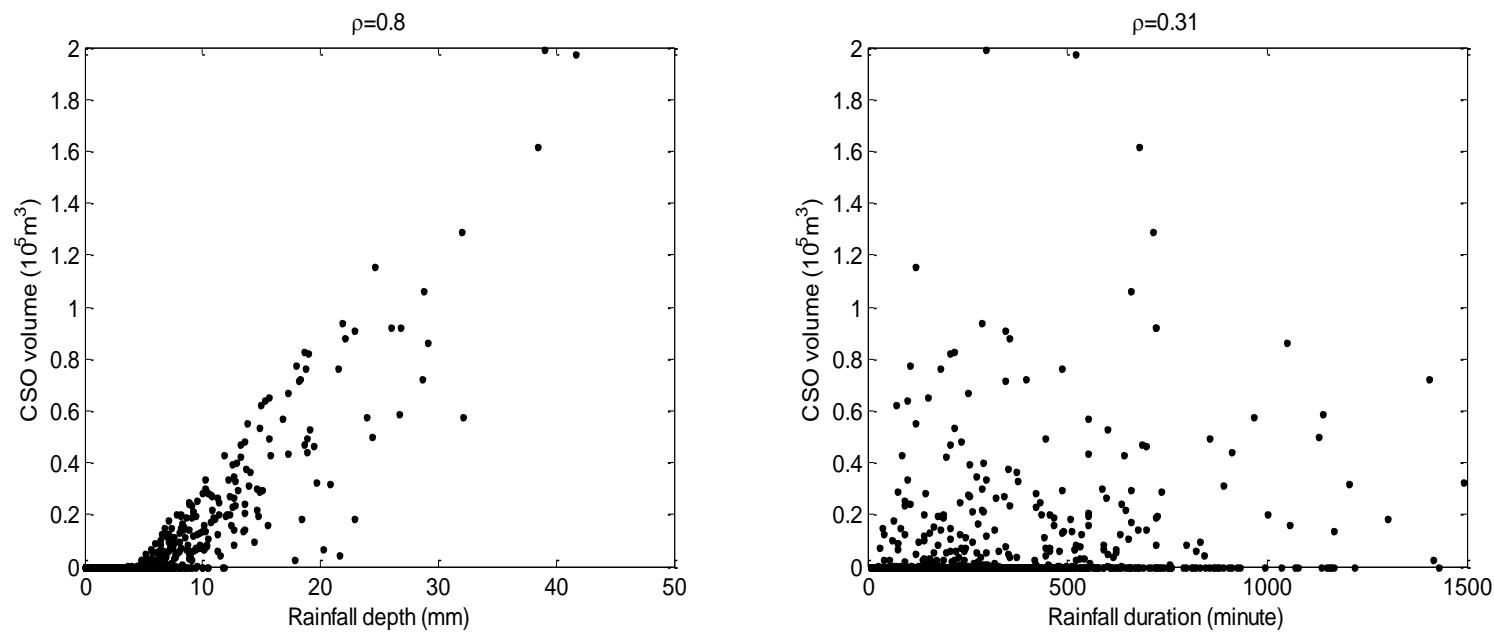


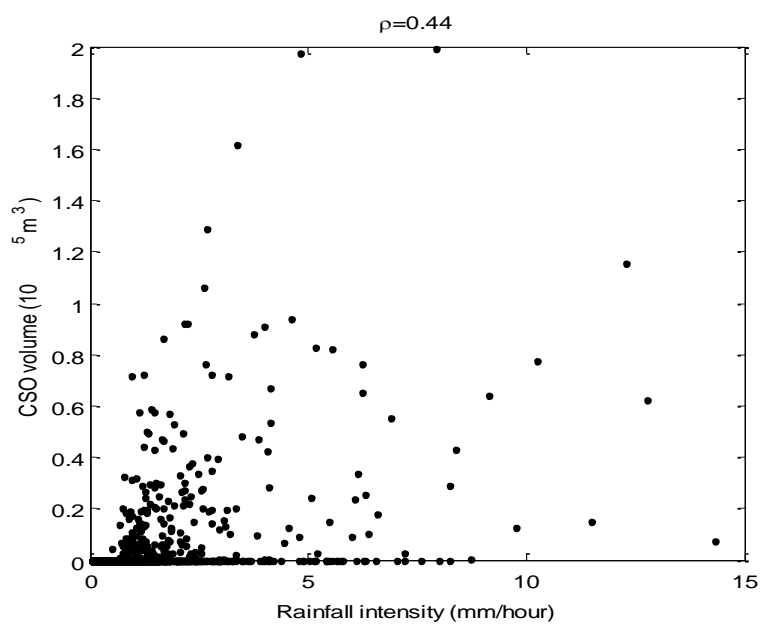

Fig. 4 Scatter plots between rainfall variables and CSO volume.

The return periods of CSO discharges are shown in Fig. 5, and these were estimated according to the cumulative distribution of CSO discharges for the simulated rainfall events and the average number of rainfall events per year. For example, for a two year return CSO discharge event, the CSO volume has a value of $0.92 \times 10^{5} \mathrm{~m}^{3}$.

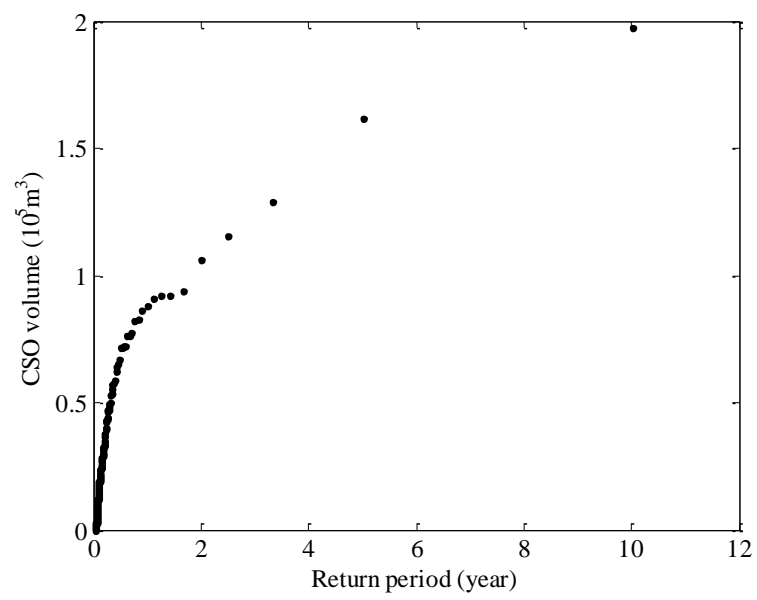

Fig. 5 Return periods of CSO volume.

\section{CONCLUSIONS}

The paper presents a study on frequency analysis of receiving water quality indicators in an integrated urban wastewater system, with the intent of assessing the system performance in terms of receiving water quality and CSO discharges. The EMC is used as a measure for the receiving water quality. The compliance frequencies for DO and ammonium EMCs at the threshold of $4 \mathrm{mg} / \mathrm{l}$ are used to assess the system performance, and are derived using the rainfall events from a series of 10 years' rainfall data.

The results obtained from the case study catchment suggest a close relationship between rainfall depth and CSO volume. However, rainfall duration and intensity have a low correlation with CSO volume. This implies that rainfall depth can be used to predict CSO volume during wet weather. Frequency analysis results show that wastewater treatment plant effluents have different impacts on DO and ammonium event mean concentrations. Further, 
CSO discharges have a low impact on the compliance probabilities for both DO and ammonium EMCs due to a low frequency CSO discharges.

The simulation results provide an understanding of the performance of the integrated system and can provide useful information to support water quality management. In this study, the integrated system is set to the default control conditions, thus the simulation results are not affected by system control or intervention measures. Future work will focus on investigation of the impacts of control strategies and engineering measures on the overall system performance, and the impact of rainfall uncertainties using probabilistic or imprecise probabilistic methods (Fu et al. 2011).

\section{ACKNOWLEDGEMENTS}

We would like to thank the reviewers for their useful comments that have greatly improved the quality of this paper.

\section{REFERENCES}

Achleitner, S., Möderl, M., and Rauch, W. 2007. CITY DRAIN@-An open source approach for simulation of integrated urban drainage systems. Environ. Modell. Softw. 22, 1184-1195.

Alp E., and Melching C.S. 2009. Evaluation of the duration of storm effects on in-stream water quality. J. Water Resour. Plann. Manage. 135(2), 107-116.

Candela, A., Freni, G., Mannina, G., and Viviani, G. 2012. Receiving water body quality assessment: an integrated mathematical approach applied to an Italian case study. Journal of Hydroinformatics 14(1), 30-47.

Council of the European Communities, 2000. Directive 2000/60/EC of the European parliament and of the council of 23 October 2000 establishing a framework for community action in the field of water policy. European Union, Luxembourg.

Even, S., Mouchel, J.M., Servais, P., Flipo, N., Poulin, M., Blanc, S., Chabanel, M., and Paffoni, C. 2007. Modelling the impacts of Combined Sewer Overflows on the river Seine water quality. Sci. Total Environ. 375 (1-3), 140-151.

Foundation for Water Research, 1998. Urban pollution management manual. 2nd edn. Foundation for Water Research, FR/CL0009, Marlow, UK.

Fu, G., Butler, D., Khu, S.T. 2008. Multiple objective optimal control of integrated urban wastewater systems. Environ. Model. Softw. 23, 225-234.

Fu, G., Butler, D., and Khu, S.T. 2009. The impact of new developments on river water quality from an integrated system modelling perspective. Sci. Total Environ. 407(4), 1257-1267.

Fu G., Khu S, Butler D. 2010. Optimal distribution and control of storage tank to mitigate the impact of new developments on receiving water quality, ASCE J. Environ. Eng. 136(3), 335-342.

Fu G., Butler D., Khu S.-T., and Sun S. 2011. Imprecise probabilistic evaluation of sewer flooding in urban drainage systems using random set theory, Water Resour. Res. 47, W02534, doi:10.1029/2009WR008944.

He, H., Zhou, J., Wu, Y.J., Zhang, W., Xie, X. 2008. Modelling the response of surface water quality to the urbanization in Xi'an, China. Journal of Environmental Management 86(4), 731-749. 
Lau, J., Butler, D., and Schütze, M. 2002. Is combined sewer overflow spill frequency/volume a good indicator of receiving water quality impact. Urban Water $\mathbf{4}(2)$, 181-189.

Ministry of Environmental Protection, 2002. Environmental quality standard for surface water. Regulation GB 3838-2002. Ministry of Environmental Protection, Beijing, People's Republic of China. (in Chinese)

Rauch, W., Bertrand-Krajewski, J.-L., Krebs, P., Mark, O., Schilling, W., Schütze, M., Vanrolleghem, P.A. 2002. Mathematical modelling of integrated urban drainage systems. Water Sci. and Technol. 45(3), 81-94.

Rauch, W., and Harremoës, P. 1998. Correlation of combined sewer overflow reduction due to real-time control and resulting effect on the oxygen concentration in the river. Water Sci. Technol. 37(12), 69-76.

Schindler, N., Tränckner, J. and Krebs, P. 2008. Assessment of river water quality criteria with integrated models and extreme value statistics. In proceeding of 11th International Conference on Urban Drainage, Edinburgh, UK.

Schütze, M. 1998. Integrated Simulation and Optimum Control of the Urban Wastewater System. PhD thesis. Department of Civil Engineering; Imperial College of Science, Technology and Medicine, University of London, London.

Semadeni-Davies, A., Hernebring, C., Svensson, G., Gustafsson, L.G. 2008a. The impacts of climate change and urbanization on drainage in Helsingborg, Sweden: Suburban stormwater. Journal of Hydrology 350, 114-125.

Semadeni-Davies A., Hernebring, C., Svensson, G., Gustafsson, L.G. 2008b. The impacts of climate change and urbanisation on drainage in Helsingborg, Sweden: combined sewer system. Journal of Hydrology 350, 100-113.

Vanrolleghem, P.A., Benedetti, L., and Meirlaen, J. 2005. Modelling and real-time control of the integrated urban wastewater system. Environ. Model. Softw. 20(4), 427-442.

Zacharof, A.I., Butler, D., Schütze, M., Beck, M.B. 2004. Screening for real-time control potential of urban wastewater systems. Journal of Hydrology 299, 349-362. 